\title{
Smart Aircraft Landing Gear: The Mechatronic Approach
}

\author{
Christophe Delebarre \\ Polytechnic University of Hauts-de-France, IEMN-DOAE, ENSIAME, Valenciennes, France
}

\section{Email address:}

christophe.delebarre@uphf.fr

\section{To cite this article:}

Christophe Delebarre. Smart Aircraft Landing Gear: The Mechatronic Approach. Journal of Electrical and Electronic Engineering. Vol. 7, No. 6, 2019, pp. 170-176. doi: 10.11648/j.jeee.20190706.16

Received: August 30, 2019; Accepted: October 11, 2019; Published: December 25, 2019

\begin{abstract}
Aircraft landing gears support the aircraft during ground operations, including take-off, landing impact, taxiing, gate handling and maintenance. In the aeronautical field, the aircraft mass repartition is a significant factor which ensures stability and safety. In order to have the best control of their device, pilots have to know the precise location of the aircraft's center of gravity, especially during critical phases such as take-off and landing. Hence, it is interesting to develop a mechatronic system able to measure in real time before take-off the mass distributed on each landing gear. This measurement provides the ability for the pilot to avoid mass overload which can have direct impacts on the structural health integrity of the aircraft. This document presents the prototyping of an embedded system which allows determining and informing in real time about the mass distribution within a lightweight aircraft by measuring the pressure inside of each shock absorber. This prototype involves the design of a specific electronic card including an embedded microcontroller, several sensors, a Bluetooth module and an Android interface for smartphones. An application has been developed to directly print on the smartphone screen the aircraft acceleration during the flight and during the landing. It actually allows estimating the pitch and the roll angles of the aircraft during the flight which are computed using the $\mathrm{X}, \mathrm{Y}$ and $\mathrm{Z}$ components of the acceleration. The two angles are represented by the aircraft pictograms.
\end{abstract}

Keywords: Landing Gear, Mass Repartition, Center of Gravity, Sensors, Microcontroller, Bluetooth Communication, Smartphone Application

\section{Introduction}

Nowadays during the flight, the landing phase of commercial aircraft is more and more a crucial part of the operational time of the plane structure, and strongly impacts the maintenance schedule. So many works on this subject have been performed and today the landing gear is more often instrumented and monitored. So the Smart Landing Gear concept has emerged and leads to a new kind of landing equipment [1-4].

This project is part of a mechatronic modeling process elaborated in collaboration with Soben, a French brand which develops landing gears for tourism aircrafts, such as Jodel lightweight aircraft [5]. This kind of aircraft is particularly used in flying club for learning and training, thanks to its small size of only a dozen meters. It is equipped with three landing gears, two at the front and one at the rear.

However, although the system presented in this paper may be in theory applied to D weight-class aircraft, we have focused here on lightweight one because we haven't access to
D class landing gear facilities. The main function of a landing gear is to support and absorb the energy induced by the weight, the ground contact and the landing impact, while ensuring maximum comfort inside the aircraft [6]. In literature, much attention has been focused on the feasibility of implementing active control technology [7-9] on hydraulic suspension systems, in order to permit better landing gear performance in a wider range of operational conditions. Interest has been shown for the reduction of both impact loads and ground roll induced vibrations [10]. In fact, the primary function of the landing gear is to absorb aircraft vertical energy during landing impact, but it must also keep the aircraft in a stable position and allow sufficient maneuverability during ground operation, which leads to conflicting requirements in terms of the suspension system. Therefore, in a static operational condition each shock absorber plays a critical role in terms of mass distribution and provides information on the aircraft's balance. Center of gravity of aircrafts is an important concern for flight stability and safety. Stating that fact, fleet maintainers and pilots are used to check weight and balance of their aircraft before taking off. That information is even 
more critical for helicopters controllability.

Nowadays, weighting scales and expensive load cells are used to obtain that information for unleaded mass. However, that process is quite long and requires space and handling, thus could not be extended for commercial flights. This is particularly true in the case of lightweight flight which could be over loaded or mass balance under estimated. Hence comes the idea of instrumenting landing gears directly, to extract in static mode weight information from pressure measurements inside oleo pneumatic shock absorbers [11, 12].

Actually, it would possible to determine the aircraft barycenter by estimating the force applied on each landing gear [13-15].

Thus, the objective of this project is to design an embedded system prototype able to measure the mass on each landing gear using pressure sensors, and to report information in real time to the user.

\section{Overview of the Test Bench}

The test bench, described in Figure 1, consists in an oleo pneumatic shock absorber on which is implanted a hydraulic jack allowing applying a force which simulates in a static mode the weight of the aircraft on the landing gear. The landing gear is equipped with three sensors:

1. A pressure sensor (EPTT5100 Variohm Eurosensor) which measures the pressure and temperature inside the shock absorber. It cannot be seen on the figure 1 because it is masked by the upper flange of the landing gear.

2. A force sensor (208C03 PCB Piezotronics) which measures the applied force on the landing gear thanks to the hydraulic jack.

3. An elongation sensor (T-PTS HT Sensor Technology) which measures the piston stroke.

This test bench is used to validate the theoretical dependance between the pressure measured inside the landing gear and the effort applied by the hydraulic jack (see part 3).
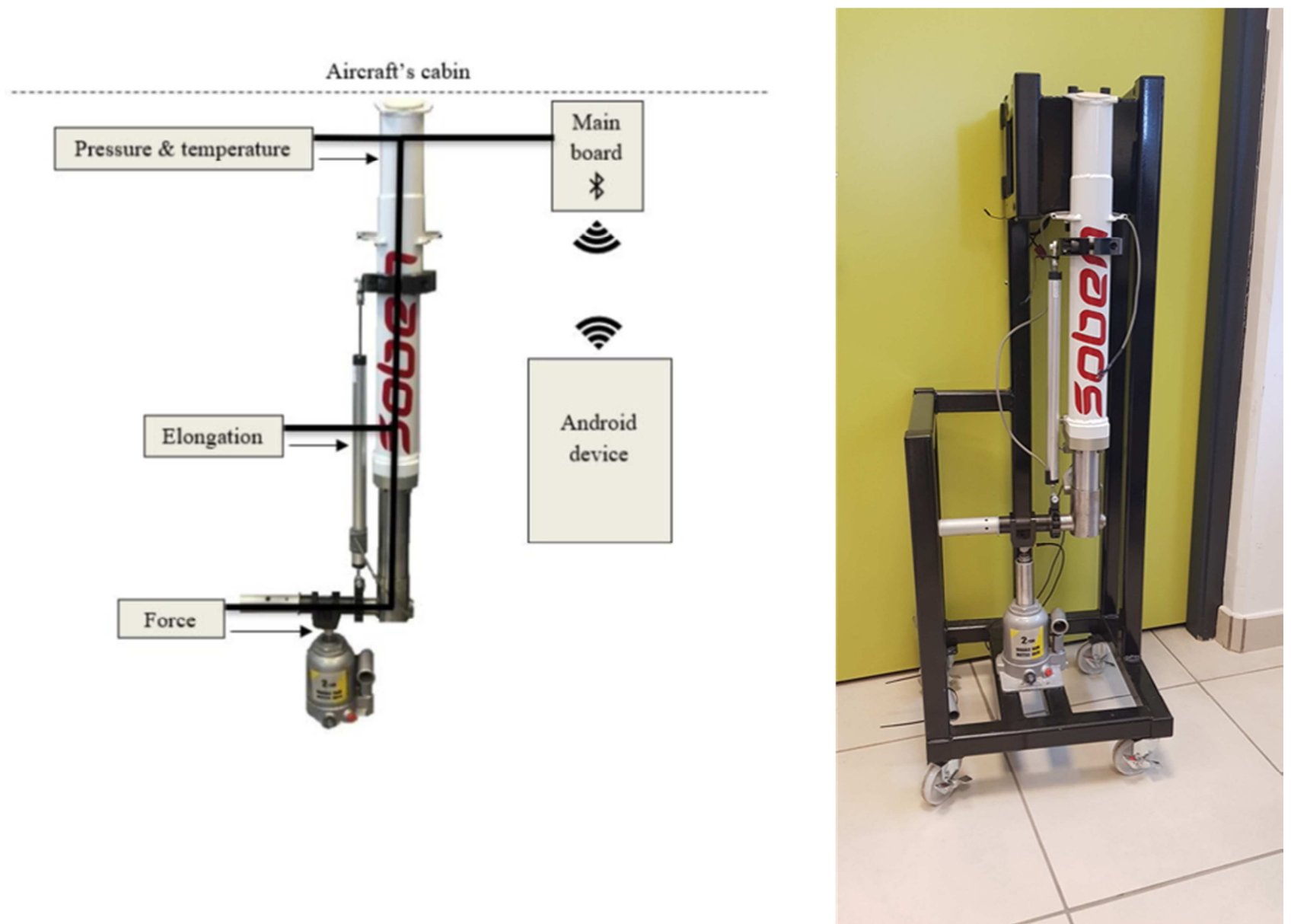

Figure 1. Schematic and photo of the landing gear test bench.

The idea is to measure the pressure inside the damper according to the applied force so as to infer the sustained mass on the landing gear. For this purpose, a pressure sensor (EPTT5100) is embedded inside the oleo part of the shock absorber and a MEM's accelerometer (ADXL 345) is applied outside. Both are connected to a specific electronic board, containing a microcontroller to digitize and process data, and a
Bluetooth module to send information to a smartphone interface (Figure 2). This Android application, connected to the main board via Bluetooth, displays a schematic view of the aircraft aiming to visualize the barycenter and the mass repartition on each landing gear. 


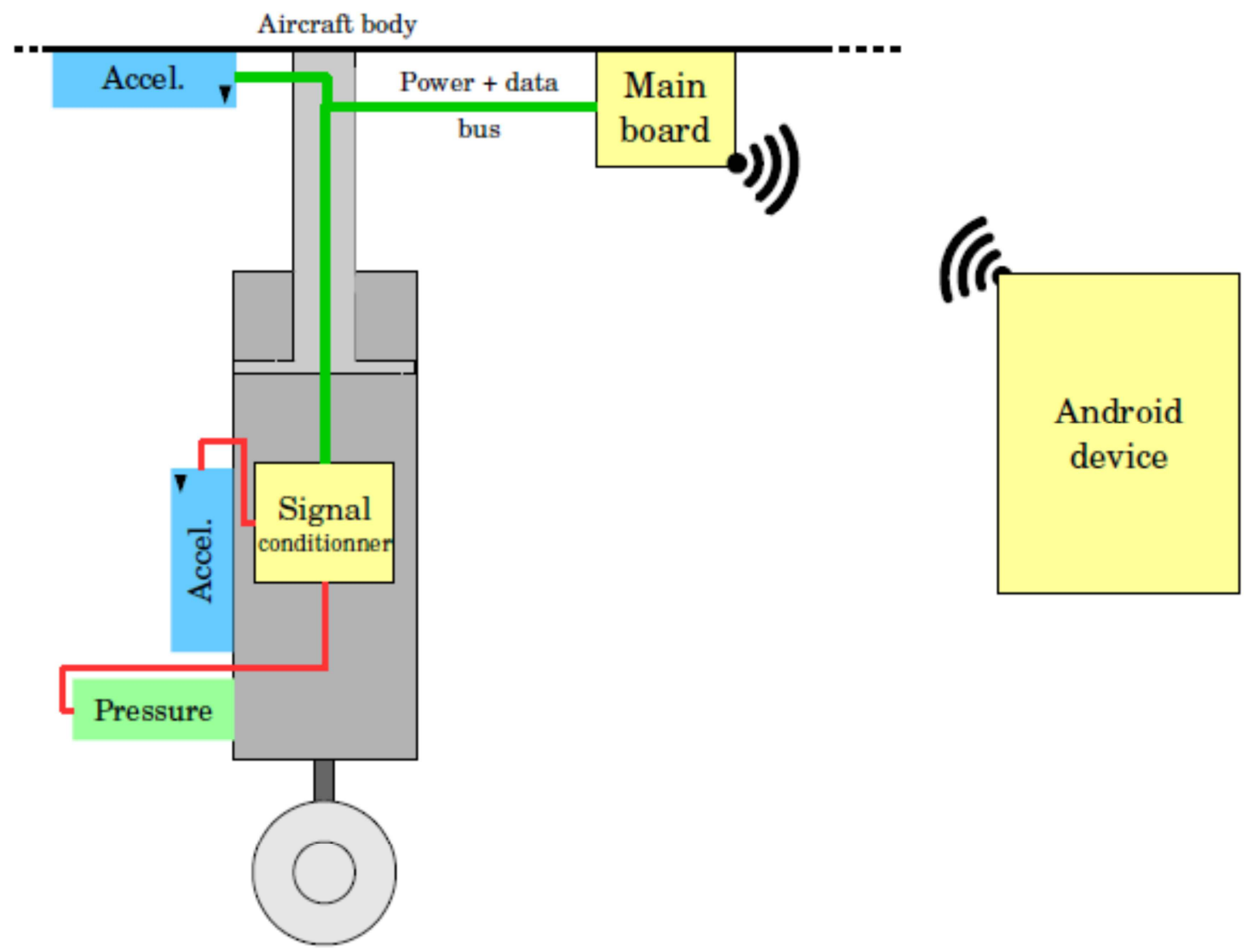

Figure 2. Overview of the prototype Smart Landing Gear.

\section{Theoretical Model and Measurement Results}

\subsection{Theoretical Model}

First of all, the shock absorber has been theoretically modeled in order to extract the mass applied to the landing gear according to the force. In this case, the only applied force corresponds to the weight of the aircraft since the study is taken from a static point of view.

As a first approximation, by applying the fundamental principle of dynamics to the piston at static equilibrium, and by writing the forces applied to the shock absorber:

$$
-(\mathrm{P}-\mathrm{P} 0) \cdot \mathrm{S}-\mathrm{M} \cdot \mathrm{g}=0
$$

With $P$ the measured air pressure, $P 0$ the initial pressure without load, $S$ the section of the piston, and $M$ the sustained mass. Therefore, the mass is given by the following formula:

$$
\mathrm{M}=-(\mathrm{P}-\mathrm{P} 0) \mathrm{S} / \mathrm{g}
$$

This expression is greatly simplified and easy to exploit. However, the study of oleo pneumatic shock absorbers is obviously much more complex and would need further calculations and hypothesis that are not necessary in this case.

\subsection{Measurements Results}

By performing several measurements on the instrumented test bed, the objective is to determine the mass applied to the landing gear according to the pressure inside the chamber, the mass being linked to the force weight of the aircraft in a static mode.

The prototype, as it has been designed, allows measuring the chamber pressure, for various initial pressures adjustable thanks to a valve, and various forces applied by the jack. Thus, by measuring both the pressure sensor voltage and the pressure inside the chamber using a manometer, we get the relationship to convert voltage into pressure (Figure 3 ).

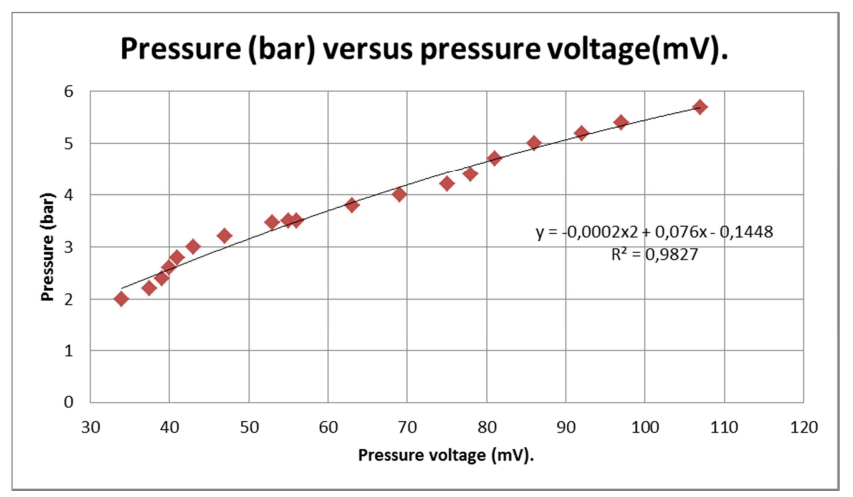

Figure 3. Pressure (bar) versus pressure voltage $(\mathrm{mV})$. 
Furthermore, knowing the sensitivity of the force sensor $(\mathrm{mV} / \mathrm{kN})$ and as the only applied force is actually the weight, it is sufficient to divide the force by the gravity acceleration to get the mass according to the pressure.

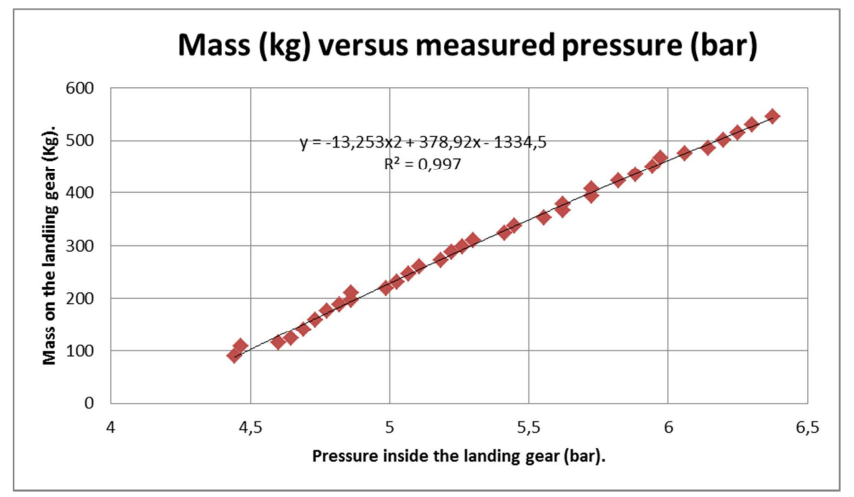

Figure 4. Mass (kg) versus pressure (bar).

Finally, this measurement procedure leads to an accurate relation between mass and pressure (coefficient $R^{2}=0.997$ ) that confirms the previous modeling. We notice that at the maximum of the admissible elongation, corresponding to a third of the piston stroke, the static mass applied is about 545 $\mathrm{kg}$ (Figure 4). Since the model has now been validated, the prototyping phase could begin.

\section{Prototyping of the System}

\subsection{Global Architecture}

As shown on Figure 5, the prototype has been developed modularly and can be divided into three main parts:

1. An acquisition board composed of the three sensors measuring pressure/temperature, elongation and force, as well as their signal electronic conditioning.

2. An embedded electronic board, processing the measured data and acting as a Bluetooth gateway.

3. A smartphone application, connected as a Bluetooth client, receiving and displaying the relevant data.

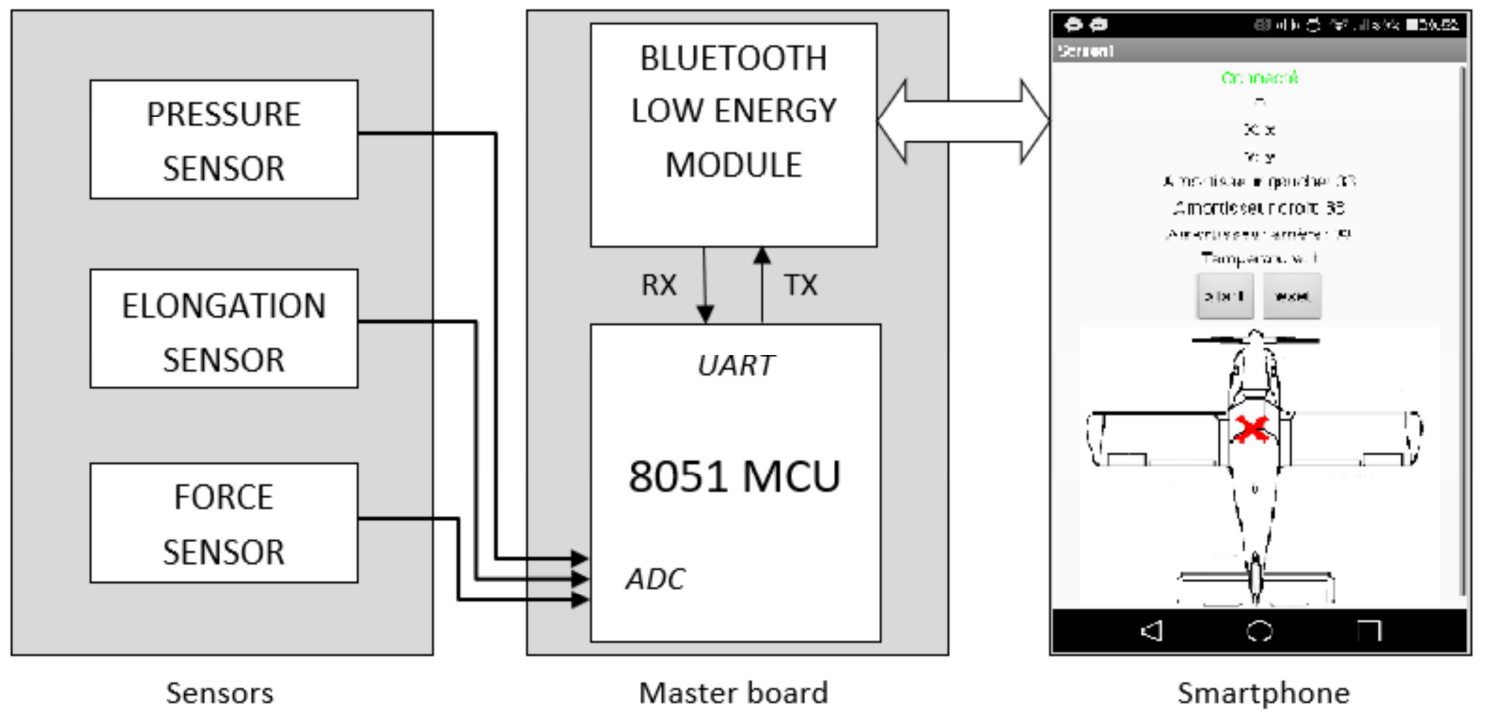

Figure 5. Prototype global architecture of the Smart Landing Gear system.

\subsection{Electronical Configuration}

The first aspect that has been worked on was to design the electronic master board, which is in charge of acquiring and converting the different signals from the sensors, processing the data and sending them by Bluetooth communication to the smartphone.

The master board is based on two main components:

1. An 8-bit microcontroller which orchestrates all tasks. A switch is connected to the pins RST/C2CLOCK and $\mathrm{C} 2 \mathrm{D}$, to be able to restart and program the microcontroller through C2 Debug Interface. Besides, the microcontroller works on its own internal system clock of $25 \mathrm{MHz}$.

2. A Bluetooth module which communicates with the microcontroller through an asynchronous serial port using RX and TX pins.
Regarding signals acquisition and treatment, a successive-approximation-register analog-to-digital converter (SAR ADC), integrated in the microcontroller, digitizes signals from the sensors and stores data into variables. The ADC is configured to measure and convert the different signals using an analog multiplexer which selects the input channels.

The electronic board has been developed under the OrCAD software (Figure 6). First of all, to draw the electrical diagram, it was necessary to define new libraries in order to create the non-existent components and their footprints. Thus, the microcontroller and the Bluetooth module are defined as boxes containing the number of associated pins, while the sensors are modeled by multi-port terminals to connect the wires. Each component is associated with a specific footprint, and the software links the component footprint with the circuit symbol. 
Then, concerning the electronic board routing, the board includes two layers, a top and a bottom. The PCB design is accomplished by manually tracing PCB tracks, respecting the constraints related to track widths and spacing. The software finally generates the BRD file in order to print and engrave the circuit board.
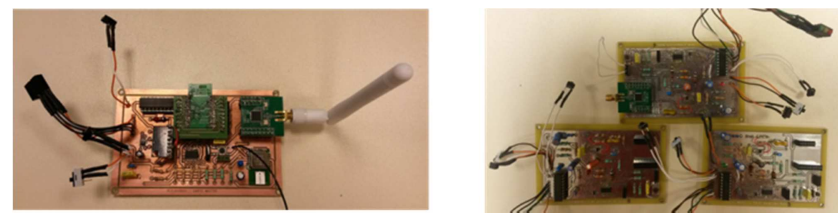

Figure 6. Main electronic board (a) and three landing gear data acquisition ones (b).

\subsection{Bluetooth Communication/Serial Port}

The data transmission between the microcontroller and the Bluetooth module is done using a serial communication interface through TX (P0.4) and RX (P0.5) pins. The serial port is configured to transmit data in 8-bit UART Mode, including 1 start bit, 8 data bits and 1 stop bit. In addition, the Timer1 is used to synchronize data transmission and configured in 8-bit Timer with Auto-Reload Mode, so as to define the transmission speed. In Auto-Reload Mode, the common speed is set at 9600 bauds.

Thus, the serial data transmission program, from the microcontroller to the Bluetooth module, contains first an initialization phase of the timer and the serial port, setting up the communication mode and speed, and then a data transmission phase using the accumulator and the serial buffer. The byte transmission starts after each writing in the serial buffer register.

\subsection{Human Machine Interface}

The application, developed for Android smartphones on the online software App Inventor, acts as a real Human Machine Interface allowing the user to visualize in real time the mass repartition on each landing gear and the center of gravity. It contains various features:

1. A Bluetooth connectivity part that allows to link two Bluetooth peripherals (the module and the smartphone).

2. A stopwatch that serves as a time counter for the application's use and as a checker in case of an application bug.

3. A data display section, including the coordinates of the aircraft's center of gravity, the percentage of load on each shock absorber, the temperature provided by the microcontroller and the acceleration values.

4. A dynamic part containing the aircraft's diagram and a cursor representing the aircraft's barycenter. This cursor moves in real time according to the location of the center of gravity.

The application sets up the Bluetooth connectivity by allowing the user to select and connect its smartphone as a Bluetooth client. When the connection is established, the connection status changes from "disconnected" to "connected".

Once the acquisition procedure and the stopwatch started, the application transmits in real time to the Bluetooth client the following data: the coordinates of the center of gravity along the transverse and longitudinal axis of the aircraft; the compression ratio of the front left, front right and rear shock absorbers; the temperature.

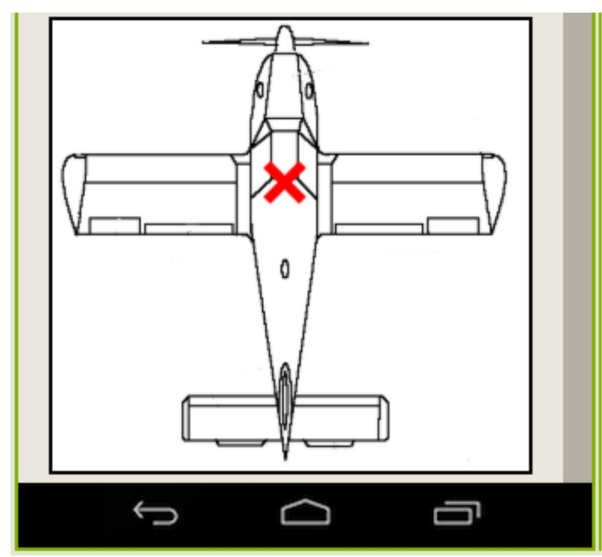

Figure 7. Graphical display.

Those data are then displayed on the graphical interface (Figure 7) and the cursor moves to the coordinates of the barycenter on the aircraft's schematic view. Because we only have one shock absorber available, Figure 7 shows the barycenter computed with one real acquisition data from the left front landing gear of $318 \mathrm{Kg}$ and two theoretical data of $320 \mathrm{Kg}$ for the right front one and $54 \mathrm{~kg}$ at the rear of the aircraft.

\section{Results and Perspectives}

The design process described above led to the creation of an electronic board which acquires signals, processes data and sends them by Bluetooth communication. For this purpose, several programs have been developed, especially to configure the ADC and the Bluetooth communication.

The main program first converts analog to digital data using the ADC, then estimates the pressure inside the shock absorber thanks to the equation obtained by the measurement procedure, and finally transmits this pressure value to the Bluetooth module using the serial port.

The application is functional. It provides data exchange between two Bluetooth devices used as a transmitter and a receiver. It also displays the location of the barycenter to the correct coordinates, as well as the load percentage on each shock absorber. This program includes lists of predefined positions inside the aircraft to which only the appropriate weight has to be assigned. An additional function allows the pilot to interact via the application and to add weights or object locations inside the aircraft. The program finally recalculates the aircraft's barycenter by considering these specificities.

Furthermore, an extended version of the program (Figure 8) has been developed to directly print on the smartphone screen 
the aircraft acceleration during the flight and during the landing. Although it is not yet exploited, this extension provides additional features. It actually allows estimating the pitch and the roll angles of the aircraft during the flight which are computed using the $\mathrm{X}, \mathrm{Y}$ and $\mathrm{Z}$ components of the acceleration. The two angles are represented by the aircraft pictograms.

Because the pressure measurement could only be made in a
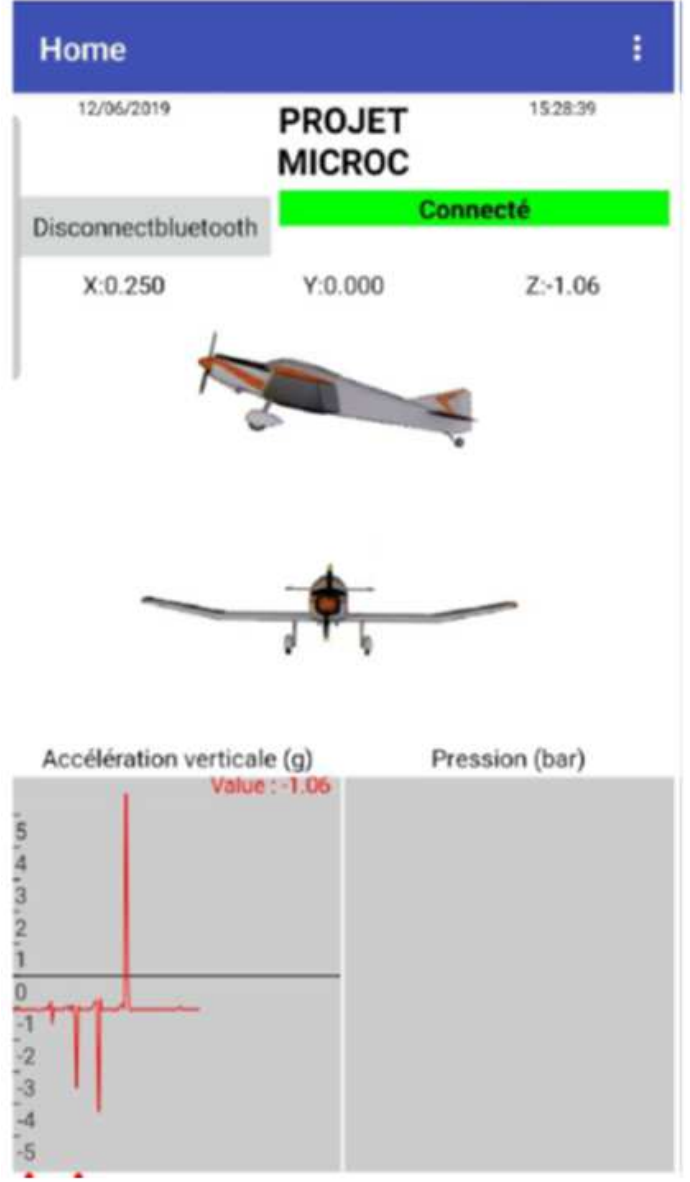

(a) static mode, the pressure data are not displayed during the flight, so no pressure data are available during the measurement of the angles during the flight.

The landing acceleration measurements (Figure 8a) have been simulated by a shock on the landing gear using the test bench and could not be associated to a real landing phase acquisition.
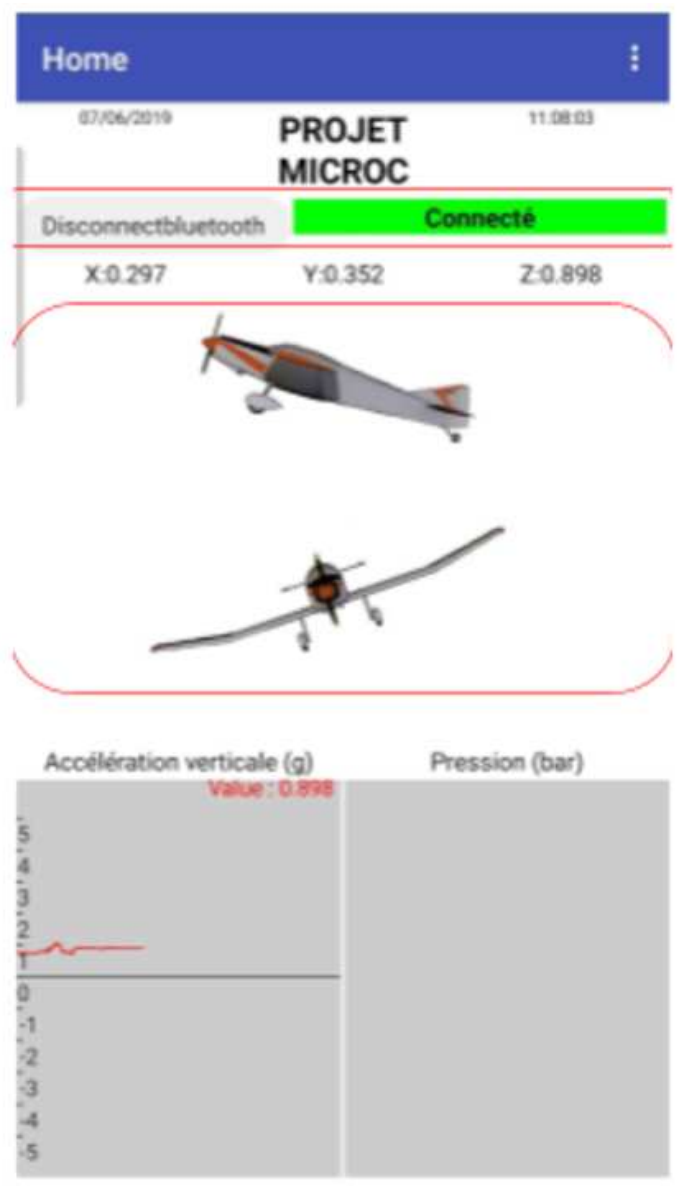

(b)

Figure 8. Aircraft acceleration measurements during landing (a) and during flight (b).

The weight of an aircraft and its balance are extremely important for operating an aircraft in a safe and efficient way [16]. When an aircraft is to be flown, the pilot must know what the loaded weight of the aircraft is, and where its loaded center of gravity is. In order for the center of gravity to be calculated, the pilot must first know the empty weight and empty weight center of gravity.

So every aircraft type certificated by the FAA, before leaving the factory for delivery to its new owner, receives a weight and balance report as part of its required aircraft records. If the weight and balance report for an aircraft is lost, the aircraft must be weighed and a new report must be created. If the airplane has new equipment installed, such as a radio or a global positioning system, a new weight and balance report must be created. If the installer of the equipment wants to place the airplane on scales and weigh it after the installation, that is a perfectly acceptable way of creating the new report.
Some aircraft are required to be weighed and have their center of gravity calculated on a periodic basis, typically every 3 years. During this 3 year period, the aircraft weighing procedure before each flight is mainly based on a computation method.

So it is very interesting to be able to compare this computed value with the measured ones collected by the Smart Aircraft Landing Gear system.

Honeywell company has developed a weight and balance system measuring aircraft huge weight and center of gravity using sensors mounted on the aircraft landing gear [17]. A dual system is capable of being certified as an alternate means of providing dispatch weight and balance information. The system is designed so that any individual component can be changed out without re-weighing the system. However no similar system is available for lightweight aircraft. 


\section{Conclusion}

This project illustrates the process of mass and barycenter estimations using pressure sensors embedded inside aircraft shock absorbers. The designed prototype is indeed able to determine the mass distribution on each landing gear thanks to pressure measurements, and to report the information in real time to the user through a smartphone application. This is a very easy way to measure the weight of the aircraft and its balance compared to the classical weighing procedure consisting in placing the aircraft and three different scales under each landing gear.

Although the system still requires some improvements, the modeling and the results obtained allow the prototyping of a full-scale model. Besides, as the device has been successfully designed for static cases, meaning when the aircraft is stopped, it would be interesting to evaluate the behavior of the system during dynamic phases such as take-off and landing. Afterwards, the following steps would involve the integration of a prototype on a real flying club aircraft.

\section{Acknowledgements}

The author would like to Florian Guégan, Ian Guéry, Corentin Laigle, Baptiste Moin, and Hajer Srihi who provided a precious help during the prototyping, the electronic board routing and the microcontroller programming, thus contributing to the success of the project.

\section{References}

[1] C. D. Berg, P. E. Wellstead, "The Application of a Smart Landing Gear Oleo Incorporating Electrorheological Fluid", Journal of Intelligent Materials Systems and Structures, Vol, Issue 8, 1998.

[2] R. Schmidt and Steven Gedeon, "Method and system for health monitoring of aircraft landing gear ", US patent: US20060144997A1, Nov 2004.

[3] W. Krüger, "Design and Simulation of Semi-active Landing Gears for Transport Aircraft", Mechanics of Structures and Machines, Volume 30, 2002 - Issue 4, pp 493-526.

[4] Haitao Wangab, J. T. Xinga, W. G. Pricea and Weiji Lib "An investigation of an active landing gear system to reduce aircraft vibrations caused by landing impacts and runway excitations", Journal of Sound and Vibration, Volume 317, Issues 1-2, 21 October 2008, pp 50-66.

[5] Jodel D-140 E, "Instruction Manual", Internal Document ACB-JMG, June 2009.
[6] Seung-Keon Kwak; Gregory Washington; and Rama K. Yedavalli, "Acceleration Feedback-Based Active and Passive Vibration Control of Landing Gear Components", Journal of Aerospace Engineering, January 2002 | Volume 15, Issue 1.

[7] G. N. Dayananda, B. Varughese and M. Subba Rao, "Shape Memory Alloy Based Smart Landing Gear for an Airship", Journal of Aircraft, Vol. 44, N.5, september-october 2007.

[8] Jan Holnicki-Szulc, C. Graczykowski, G. Mikułowski, A. Mróz, P. Pawłowski, "Smart Technologies for Adaptive Impact Absorption", Solid State Phenomena, Vol. 154, pp. 187-194, 2009.

[9] Grzegorz M Mikułowski and Jan Holnicki-Szulc, "Adaptive landing gear concept-feedback control validation", Smart Material and Structure, Vol. 16, N. 6, 2007.

[10] HaitaoWangab J. T. XingaW. G. Pricea Weiji Lib, “An investigation of an active landing gear system to reduce aircraft vibrations caused by landing impacts and runway excitations", Journal of Sound and Vibration, Vol. 317, Issues1-2, pp 50-66, 2008.

[11] Christophe. Delebarre, Sébastien. Grondel, Samuel. Dupond et al. "Wireless monitoring system for lightweight aircraft landing gear", September 2017, DOI: 10.1109/REM.2017.8075230, 2017 International Conference on Research and Education in Mechatronics (REM2017).

[12] G. Mikulowski and J. Holnicki-Szulc, "Adaptive aircraft shock absorbers", AMAS Workshop on Smart Materials and StructuresSMART'03 - (pp. 63-72) - Jadwisin, September 2-5, 2003.

[13] Jan Holnicki-Szulc, C. Graczykowski, G. Mikułowski, A. Mróz, P. Pawłowski, "Smart technologies for adaptive impact absorption", Solid State Phenomena (Volume 154), Smart Materials for Smart Devices and Structures, Edited by Marcin Leonowicz and Dariusz Oleszak, pp 187.

[14] S. J. Cowan, R. L. Cox, H. W. Slusher, S. Jinadasa, "Airplane hard landing indication system", US Patent 6,676,075. January 2004.

[15] Wolf R. Krüger, Marco Morandini, "Recent developments at the numerical simulation of landing gear dynamics", CEAS Aeronautical Journal, September 2011, Volume 1, Issue 1-4, pp $55-68$.

[16] «Needs and Requirements for Aircraft Weighing», FAA-8083-30-CH_04, 2016 US department of transportation Federal Aviation Administration.

[17] https://aerospace.honeywell.com/en/products/navigation-and-s ensors/weight-and-balance. 